PREPARED FOR THE U.S. DEPARTMENT OF ENERGY, UNDER CONTRACT DE-AC02-76CH03073

PPPL-3718

PPPL-3718

UC-70

Initial Neutral Particle Analyzer Measurements

of Ion Temperature in NSTX

by

S.S. Medley, R.E. Bell, M.P. Petrov,

A.L. Roquemore, and E.V. Suvorkin

July 2002

NM|

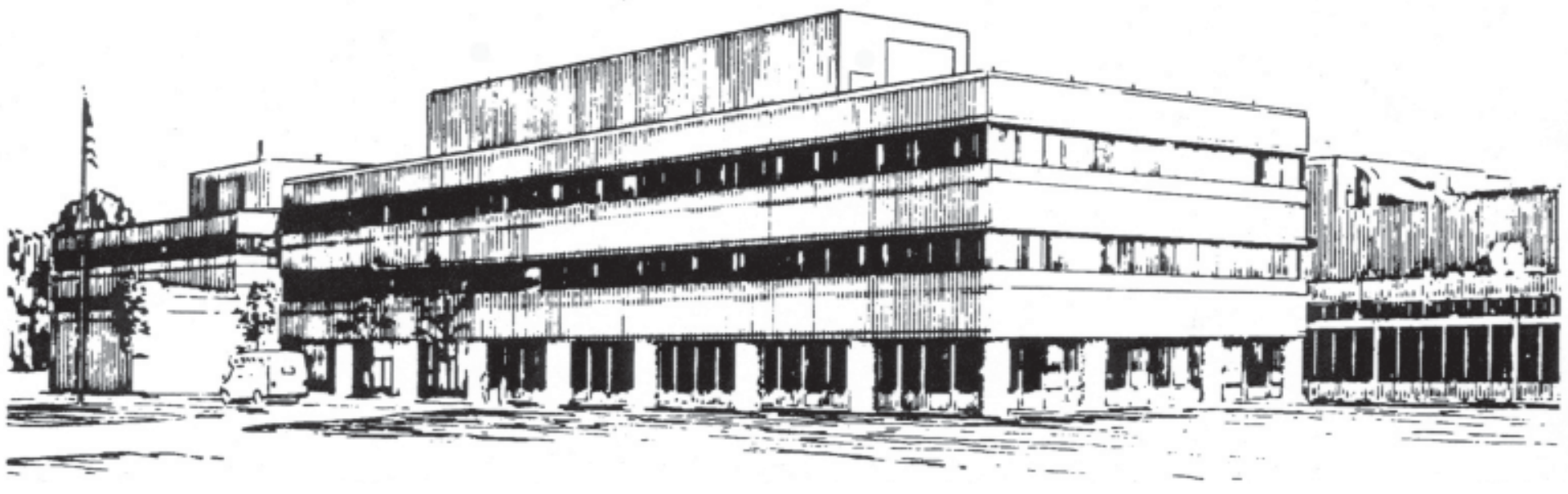

PRINCETON PLASMA PHYSICS LABORATORY PRINCETON UNIVERSITY, PRINCETON, NEW JERSEY 


\section{PPPL Reports Disclaimer}

This report was prepared as an account of work sponsored by an agency of the United States Government. Neither the United States Government nor any agency thereof, nor any of their employees, makes any warranty, express or implied, or assumes any legal liability or responsibility for the accuracy, completeness, or usefulness of any information, apparatus, product, or process disclosed, or represents that its use would not infringe privately owned rights. Reference herein to any specific commercial product, process, or service by trade name, trademark, manufacturer, or otherwise, does not necessarily constitute or imply its endorsement, recommendation, or favoring by the United States Government or any agency thereof. The views and opinions of authors expressed herein do not necessarily state or reflect those of the United States Government or any agency thereof.

\section{Availability}

This report is posted on the U.S. Department of Energy's Princeton Plasma Physics Laboratory Publications and Reports web site in Fiscal Year 2002. The home page for PPPL Reports and Publications is: http://www.pppl.gov/pub_report/

DOE and DOE Contractors can obtain copies of this report from:

U.S. Department of Energy

Office of Scientific and Technical Information

DOE Technical Information Services (DTIS)

P.O. Box 62

Oak Ridge, TN 37831

Telephone: (865) 576-8401

Fax: (865) 576-5728

Email: reports@adonis.osti.gov

This report is available to the general public from:

National Technical Information Service

U.S. Department of Commerce

5285 Port Royal Road

Springfield, VA 22161

Telephone: 1-800-553-6847 or

(703) 605-6000

Fax: (703) 321-8547

Internet: http://www.ntis.gov/ordering.htm 


\title{
Initial Neutral Particle Analyzer Measurements of lon Temperature in NSTX
}

\author{
S. S. Medley, R. E. Bell, M. P. Petrov ${ }^{+}$A. L. Roquemore and E. V. Suvorkin ${ }^{+}$ \\ Princeton Plasma Physics Laboratory, Princeton, New Jersey, 08543, USA \\ ${ }^{+}$A. F. Ioffe Physical-Technical Institute, St. Petersburg 194021, Russia
}

\begin{abstract}
The Neutral Particle Analyzer (NPA) diagnostic on the National Spherical Torus Experiment (NSTX) utilizes a PPPL-designed E||B spectrometer which measures the energy spectra of minority $\mathrm{H}$ and bulk $D$ species simultaneously with 39 energy channels per mass specie and a time resolution of 1 msec. The calibrated energy range is $\mathrm{E}=0.5-150 \mathrm{keV}$ and the energy resolution varies from $\Delta \mathrm{E} / \mathrm{E}=$ $3-7 \%$ over the surface of the microchannel plate detector. The NPA measures thermal Maxwellian ion spectra to obtain line integrated ion temperatures, $T_{i}$. For line integral electron densities below $n_{e} L \sim 3.5$ $x 10^{19} \mathrm{~m}^{-2}$, good agreement is observed between the line integrated NPA $T_{i}$ and the central $T_{i}(0)$ measured by the spatially localized CHarge Exchange Recombination Spectroscopy (CHERS) diagnostic. However, with increasingly higher $n_{e} L$ the NPA $T_{i}$ falls below the central $T_{i}(0)$ measured by CHERS because the charge exchange neutral emissivity weights the line integrated NPA measurement outboard of the plasma core. An analytic neutral analysis code, DOUBLE, has been applied to the NPA data to correct for this effect and restore agreement with $T_{i}(0)$ measured by CHERS. A description of the NPA diagnostic on NSTX and initial ion temperature measurements along with an illustration of application of the DOUBLE code are presented.
\end{abstract}

\subsection{Introduction}

The National Spherical Torus Experiment (NSTX) is a low aspect ratio $(R / a \sim 1.3)$ device with auxiliary heating from Neutral Beam Injection (NBI) and High Harmonic Fast Wave (HHFW) heating. Typical NSTX parameters are $R_{0}=85 \mathrm{~cm}, a=67 \mathrm{~cm}, I_{p}=0.7-1.4 \mathrm{MA}, B_{f}=0.35-0.60 \mathrm{~T}$. Three codirected deuterium neutral beam sources have injected up to $P_{N B} \sim 7 \mathrm{MW}$ at injection energies up to $E_{N B} \sim 100 \mathrm{keV}$. HHFW heating at $f_{R F} \sim 30 \mathrm{MHz}$ has delivered up to $P_{R F} \sim 6 \mathrm{MW}$ to $\mathrm{D}$ and He plasmas. Important to the understanding of ion behavior in NSTX are the Neutral Particle Analyzer (NPA) and the Charge Exchange Recombination Spectroscopy (CHERS) diagnostics. The NPA diagnostic utilizes a PPPL-designed E ||$B$ spectrometer[1] which measures the energy spectra of $\mathrm{H}^{+}$and $\mathrm{D}^{+}$ion species simultaneously with a time resolution of $\sim 1 \mathrm{msec}$ set by signal-to-noise levels. The calibrated energy range is $\mathrm{E}=0.5-150 \mathrm{keV}$ and the energy resolution varies from $\Delta \mathrm{E} / \mathrm{E}=7 \%$ at low $\mathrm{E}$ to $\Delta \mathrm{E} / \mathrm{E}=3 \%$ at high E. The detector consists of a large area microchannel plate (MCP) which is provided with two rectangular, semi-continuous active area strips, one coinciding with each of the mass rows for detection 
of $\mathrm{H}^{+}$and $\mathrm{D}^{+}$and each mass row has 39 energy channels. The NPA measures Maxwellian spectra of residual $\mathrm{H}^{+}$to obtain ion temperatures, $\mathrm{T}_{\mathrm{i}}$, and $\mathrm{D}^{+}$ energetic ion spectra produced by injection of up to $100 \mathrm{keV} \mathrm{D}$ neutral beams into a $D$ plasma. The CHERS system[2] measures carbon ion temperature, $T_{i},(r)$, and toroidal flow, $V_{f}(r)$, during

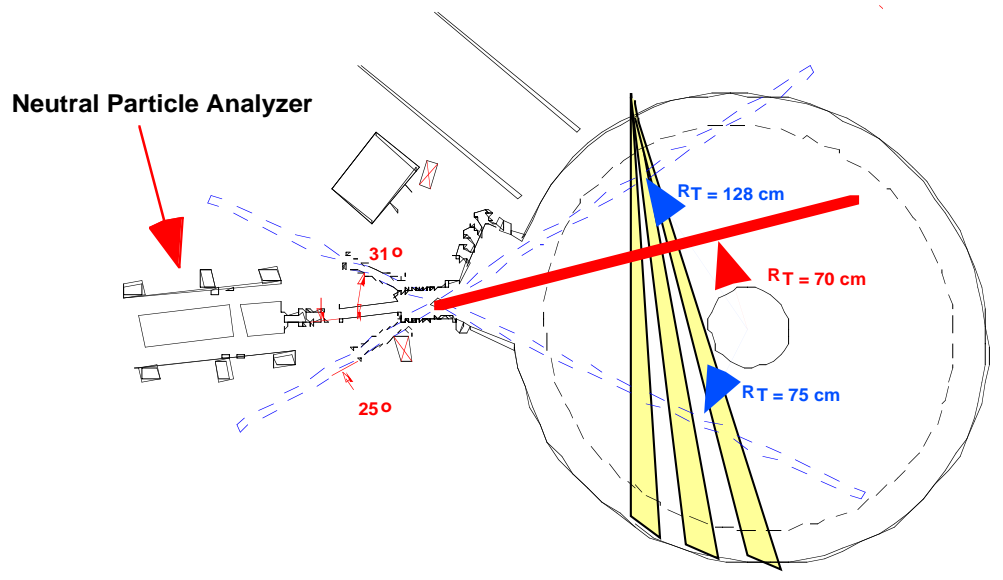
$\mathrm{NBI}$ at 17 radial positions spanning the outer half of the minor Figure 1. Layout of the Neutral Particle Analyzer on NSTX. radius with $20 \mathrm{~ms}$ time resolution.

The three neutral beam lines on NSTX inject at $R_{\text {tan }}$ of $70 \mathrm{~cm}$ (source A), $60 \mathrm{~cm}$ (source B) and $50 \mathrm{~cm}$ (source C). Initially, the NPA was installed with a fixed sightline having $R_{\tan }=70 \mathrm{~cm}$ which views across the neutral beam lines at co-directed ions as shown by the solid chord in Figure 1. Subsequently, the NPA was upgraded to provide horizontal scanning as shown by the dashed chords as well as vertical scanning to view below the plasma midplane.

\subsection{NPA Ion Temperature Measurements}

Since NSTX uses deuterium for both the neutral beams and the plasma discharge, it is necessary to measure the spectra of the residual $\mathrm{H}^{+}$ions in order to obtain NPA ion temperature measurements. An example of the NPA time evolution of $T_{i}$ is shown in the upper panel of Figure 2 for NSTX discharge SN106031 along with the CHERS central ion temperature, $T_{i}(0)$. Examples of the NPA thermal hydrogen ion spectra are presented later in this paper. The center panel shows waveforms for electron temperature and density from the Multi-Pulse Thomson Scattering (MPTS) system as well as the injected neutral beam power, plasma current and a Mirnov coil trace indicating magnetohydrodynamic (MHD) activity. The CHERS profiles during NB heating show $T_{i}$ profiles that are typically hotter and broader than $T_{e}$ profiles [2] as shown in the bottom panel of Figure 2 for time $t=270$ msec in the discharge. The agreement of the line-integral NPA $T_{i}$ measurements with the localized CHERS central ion temperature, $T_{i}(0)$, is no doubt abetted by the broadness of the $T_{i}$ profiles.

It can be seen that the line integrated NPA and core CHERS ion temperature measurements are in good agreement up to $\mathrm{t} \sim 230 \mathrm{msec}$, after which time the data for the NPA falls below that for 

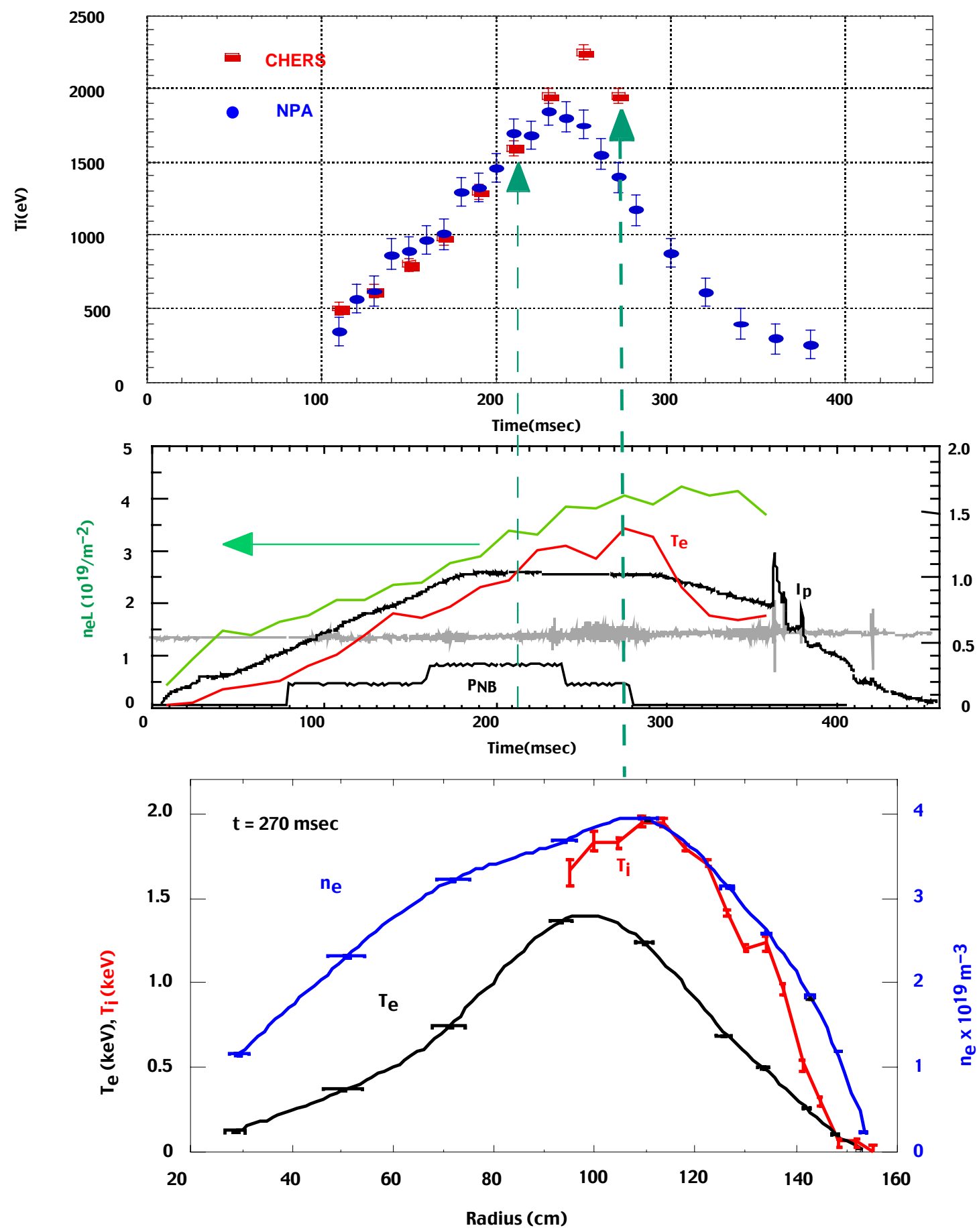

Figure 2. Ion temperature evolution measured by the NPA and CHERS diagnostics for discharge SN106031 (top panel), selected discharge waveforms (center panel). Multi-Pulse Thomson Scattering(MPTS) profiles of $n_{e}$ and $T_{e}$ and the CHERS $T_{i}$ profile are shown in the bottom panel for time $t=270 \mathrm{msec}$. 
CHERS. To examine this behavior further, a data base of NPA and CHERS measurements comprised of 12 discharges with ion temperatures measured at $\sim 8$ time points in each discharge was constructed. The result shown in Figure 3 reveals that the two measurements are in reasonable agreement (indicated by the dashed line) for ion temperatures up to $\sim 1500 \mathrm{eV}$, above which the core CHERS value exceeds that of the line-integrated NPA. By examining the database electron density traces such as shown in the center panel of Figure 2, it was established that this roll off correlated with the line integral density exceeding $\mathrm{n}_{\mathrm{e}} \mathrm{L} \sim 3.5 \times 10^{19} \mathrm{~m}^{-2}$.

It is a well know shortcoming of line-integrated NPA ion temperature measurements that if the plasma opacity, $\overline{\mathrm{n}}_{\mathrm{e}} \sigma_{C X}$ a, becomes too large [3] then the observed $T_{i}$ underestimates the core $T_{i}(0)$. If the neutral flux is sufficiently large to enable ion temperature measurements in the energy range $E / T_{i}(0) \sim 5-10$, then $T_{i}$ from the slope of the NPA thermal ion spectrum differs from $\mathrm{T}_{\mathrm{i}}(0)$ by not more than $10-15 \%$ up to a plasma average density given by $\overline{\mathrm{n}}_{\mathrm{e}} \sigma_{C X}$ a 10 which for NSTX would be $\overline{\mathrm{n}}_{\mathrm{e}} \sim 10^{20}$ $\mathrm{m}^{-3}$. However, because the residual $\mathrm{H}^{\mathrm{O}}$ density in NSTX is low $\left(\mathrm{H}^{\mathrm{O}} / \mathrm{D}^{\mathrm{O}} \sim 5 \%\right)$, the neutral flux is adequate to measure $T_{i}$ only

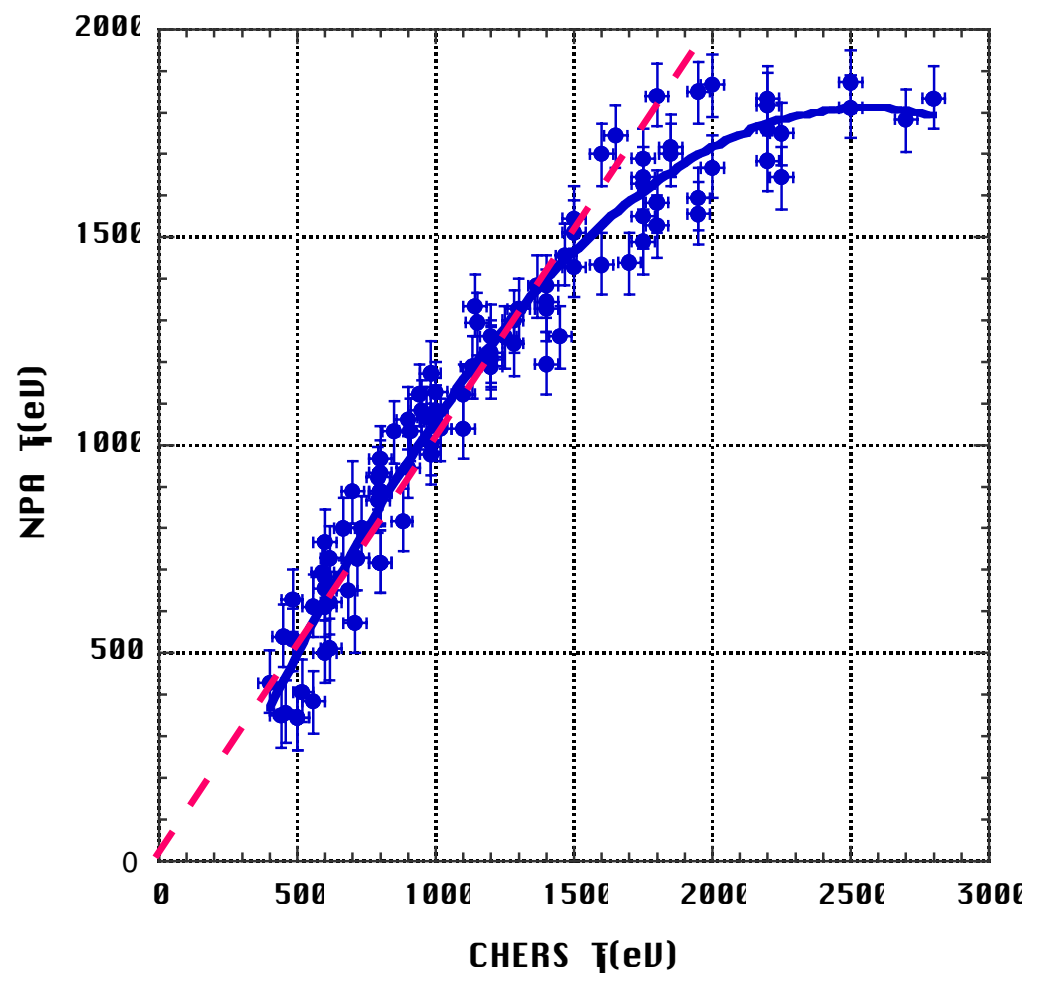

Figure 3. Comparison of ion temperature measurements from the NPA and CHERS diagnostics. The solid curve is a simple fit to the data while the dashed line corresponds to equality between the two measurements.

in the energy range $E / T_{i}(0) \sim 2-5$. This leads to $T_{i}<T_{i}(0)$ at significantly lower $\bar{n}_{e}$, experimentally determined to be $\bar{n}_{e} \sim 3 \times 10^{19} \mathrm{~cm}^{-3}$ corresponding to $\mathrm{n}_{\mathrm{e}} \mathrm{L} \sim 3.5 \times 10^{19} \mathrm{~m}^{-2}$ in the center panel of Figure 2 . This interpretation of the NPA ion temperature behavior was verified by application of the neutral particle analysis code DOUBLE to the situation as described in the next section.

\subsection{Analysis of NPA Thermal lon Measurements using the DOUBLE Code}

The DOUBLE code[4] was developed at the loffe Institute to calculate neutral particle flux escaping from a plasma and detected by a neutral particle analyzer. This is accomplished in two steps: first the neutral particle density distribution over the plasma volume is calculated and then integration along the NPA line of sight is performed. 
The Bolzmann kinetic equation describing the neutral particle distribution $f(\vec{x}, \vec{v})$ over position, $\vec{x}$, and velocity, $\vec{v}$, space is assumed to be time-independent:

$$
\begin{aligned}
& \vec{v} \frac{\partial f(\vec{r}, \vec{v})}{\partial \vec{r}}+n_{e} f(\vec{r}, \vec{v})\langle\sigma v\rangle_{e}+f(\vec{r}, \vec{v}) \int \varphi_{i}\left(\vec{r}, \vec{v}^{\prime}\right) \sigma_{C X}\left(\left|\vec{v}-\vec{v}^{\prime}\right|\right) \vec{v}-\vec{v}^{\prime} \mid d v^{\prime}= \\
& \varphi_{i}(\vec{r}, \vec{v}) \int f\left(\vec{r}, \vec{v}^{\prime}\right) \sigma_{C X}\left(\left|\vec{v}-\vec{v}^{\prime}\right|\right) \vec{v}-\vec{v}^{\prime} \mid d v^{\prime}+n_{e} \varphi_{i}(\vec{r}, \vec{v})\langle\sigma v\rangle_{r}+S(\vec{r}, \vec{v})
\end{aligned}
$$

where $\varphi_{i}(\vec{r}, \vec{v})$ is the ion velocity distribution function, $\langle\sigma v\rangle_{e}$ and $\langle\sigma v\rangle_{r}$ are the electron ionization and recombination rate coefficients correspondingly, $n_{e}$ is the electron density, $\sigma_{C X}$ is the charge exchange cross-section and $S(\vec{r}, \vec{v})$ is the neutral source distribution function. The source term may include local neutral particle sources such as pellet or neutral beam injection. Other neutral sources generated by wall recycling are allowed for in boundary conditions. It must be stressed that all of the distribution functions when integrated over both parameters give corresponding particle densities.

The kinetic equation generally can be solved in two ways. Firstly it can be reduced to an integral equation for the neutral density using a simplified plasma model, e.g., one-dimensional geometry, deltafunction as the ion velocity distribution, simplified boundary conditions (uniform wall flux resulting from recycling process). The integral equation then can be solved numerically. This method will be referred to as an analytic one. An alternative approach is to use Monte Carlo methods to integrate the kinetic equation. This is a very powerful tool for including the complicating effects of asymmetries, Maxwellian (and non-Maxwellian) plasmas, and detailed atomic and wall physical processes.

Charge exchange atomic flux escaping the plasma is given by

$$
J_{a}(E)=\int_{L O S}\langle\sigma v\rangle_{C X} n_{0}(\vec{r}) \varphi_{i}(\vec{r}, E) \mu(\vec{r}, E) d l
$$

where $n_{0}$ is the neutral particle density obtained previously, $\mu(\vec{r}, E)$ is the plasma attenuation factor for a neutral formed in a charge exchange event and $E$ is the neutral energy.

The analytic approach was implemented in the code called DOUBLE. The code simulates three species (two hydrogen and one helium), one-dimensional (cylindrical), stationary plasma. The integral equation for neutral density is solved using the method of successive approximations. Neutral edge density and edge temperature are used as uniform boundary conditions. Although the passive neutral density distribution is simulated in one-dimensional geometry, the rest of the code uses 3D geometry.

In order to simulate NSTX NPA experimental data some modifications to DOUBLE code have been made. The core part of the code that deals with neutral particle transport and calculates the passive neutral density distribution was not affected. The code was modified to simulate horizontal 
propagation of the three neutral beam sources in the midplane on NSTX, active charge-exchange events of plasma ions on the three energy components of the beam primary neutrals (and halo neutrals) and the outgoing neutral flux attenuation. The beam density was treated as a two-dimensional Gaussian distribution given by

$$
n(x, y)=\frac{N \cdot \exp \left(-\frac{x^{2}}{e w^{2}}-\frac{y^{2}}{e h^{2}}\right)}{\pi \cdot e w \cdot e h \cdot \operatorname{erf}\left(\frac{f w}{2 e w}\right) \cdot \operatorname{erf}\left(\frac{f h}{2 e h}\right)},
$$

where $f w$ and $f h$ are beam full width and full height, $e w$ and $e h$ are e-folding half widths in radial and vertical direction correspondingly, $N$ is beam linear density. The halo neutral density ( $1^{\text {st }}$ generation) was deduced from the following balance equation:

$$
n_{\text {beam }} n_{i} \cdot \sigma_{c x} v_{\text {beam }}=\frac{n_{\text {halo }}}{\tau}
$$

where $\tau$ stands for halo neutral "lifetime" (typical time for a halo neutral to be ionized). The left-hand part represents halo neutral formation rate (gain) and the right-hand part gives the decay rate (loss). Neutral flux produced by charge-exchange events on halo neutrals can be found in the same manner as in the case of the primary beam neutrals. The angle between beam direction and that of the NPA sightline is assumed to be 90 degrees and the NPA sightline is also constrained to lie in the midplane.

To estimate active NPA flux, the code at first calculates the beam attenuation factor along its chord and the corresponding neutral density value is used in the integration procedure along the NPA sightline while taking into account charge-exchange reaction rate. Only the beam-sightline intersection region in the plasma contributes to the active flux.

The attenuation factor (i.e. the probability for a neutral penetrating plasma from its surface to reach the $\vec{r}$ point or the probability for a neutral starting from the $\vec{r}$ point to leave plasma column) can be represented by:

$$
\mu(\vec{r})=\exp \left(-\frac{1}{v} \int_{(L)}^{\vec{r}} n\langle\sigma v\rangle_{a t t} d l\right)
$$

(where $v$ is the neutral velocity). The emissivity is given by

$$
\varepsilon_{\text {act }}(\vec{r}, E)=\frac{1}{4 \pi} n_{\text {beam }}^{0} \cdot \mu_{\text {beam }}(\vec{r}) \cdot n_{i} \sigma_{c x} v_{\text {beam }} \cdot \varphi_{i}(E)
$$

where $n_{\text {beam }}^{0}$ is the initial beam density, $\varphi_{i}(E)$ is plasma ion energy distribution (e.g. Maxwellian). So the active flux is given by

$$
J_{a c t}=\int_{\left(L_{N P A}\right)} \varepsilon_{a c t} \cdot \mu_{0} d l
$$


The inputs to the code include geometrical parameters for the NSTX device and the layout of the neutral beams and the NPA diagnostic. The plasma is characterized by electron density, electron temperature and ion temperature profiles, effective charge value, major and minor radius values etc. The profile data, an example of which is given in the bottom panel in Figure 2, is usually parameterized in a parabolic form:

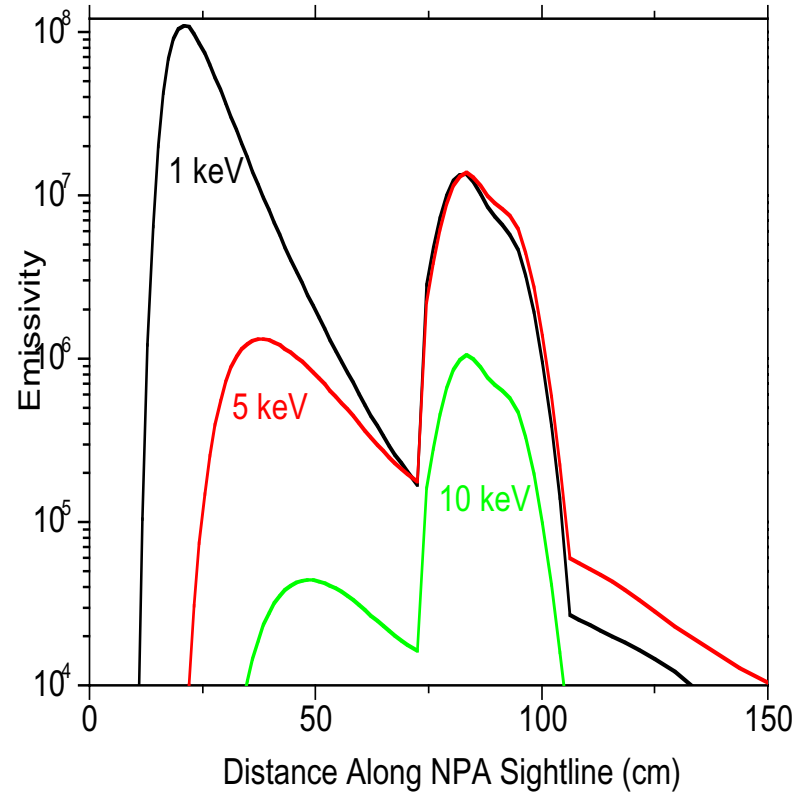

Figure 4. Example of the emissivity calculated by the DOUBLE code, including passive and active neutral particle sources, versus distance along the NPA sightline.

$$
T(r)=T(0) \cdot\left(1-\left(\frac{r}{a}\right)^{Y 1}\right)^{Y 2} .
$$

The main outputs are neutral particle radial profiles, the so-called emissivity functions and the neutral spectra. The emissivity function represents the probability that a neutral particle of particular energy born at particular location escapes the plasma volume.

The DOUBLE code was used to simulate the NPA measurements for NSTX discharge SN106031 at times $t$ $200 \mathrm{msec}$ and $\mathrm{t} \sim 270 \mathrm{msec}$ as indicated by the dashed vertical lines in Figure 2 . The calculated emissivity function including active beam primary and halo neutrals and passive neutrals is shown in

Figure 4 for the charge exchange emission at energies of 1,5 and $10 \mathrm{keV}$. The contribution from the neutral beams (Sources $B$ and $C$ ) is evidenced by the peaks in the region of $75-100 \mathrm{~cm}$ along the NPA sightline. The minority hydrogen spectra for the NPA measurements (solid squares) and the DOUBLE code simulations (solid and dashed lines) are shown in Figure 5 for discharge time $t \sim 200$ msec and in Figure 6 for $\mathrm{t} \sim 270 \mathrm{msec}$. In Figure 5, the individual contributions from neutral beam sources $\mathrm{B}$ and $\mathrm{C}$ and the passive neutrals to the total spectrum are shown. Good agreement is obtained with $\mathrm{T}_{\text {code }} \sim 1500$ $\mathrm{eV}$ compared with $\mathrm{T}_{\text {CHERS,NPA }} \sim 1500 \mathrm{eV}$ from Figure 2 which benchmarks proper functioning of the code. In Figure 6, the core input temperature to the code was varied between $1300 \mathrm{eV}$ and $2300 \mathrm{eV}$. The best code fit to the NPA data is obtained with $\mathrm{T}_{\text {code }} \sim 1700-2000 \mathrm{eV}$ compared with the measured CHERS value of $T_{\text {CHERS }}=1900 \mathrm{eV}$. As seen in Figure 2, the ion temperature obtained from the slope of the measured NPA spectrum was considerably lower at $T_{\mathrm{NPA}}=1400 \mathrm{eV}$. Thus the DOUBLE code modeling of the NPA measurements at high $n_{e} L$ restores agreement with the CHERS Ti(0). 


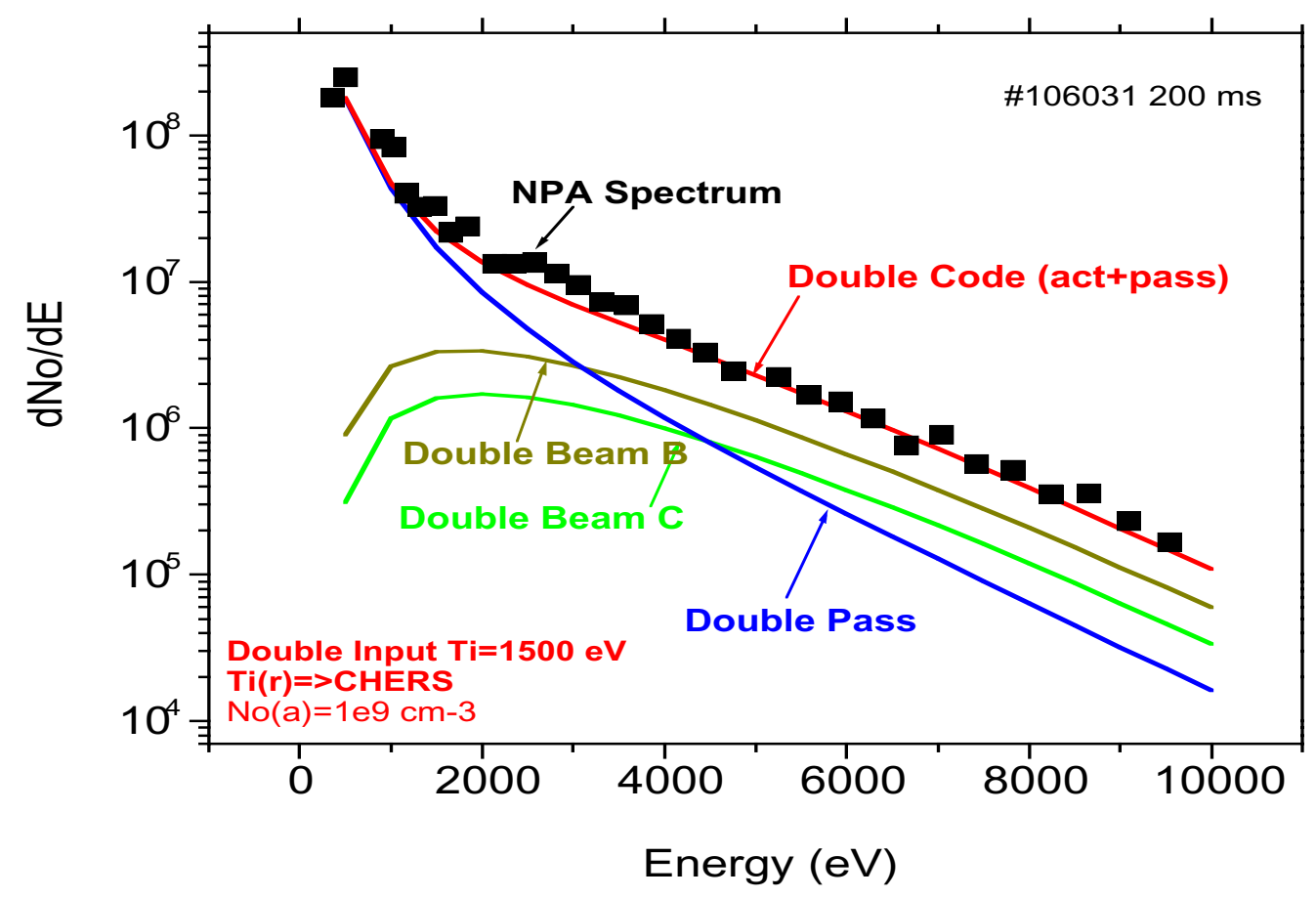

Figure 5 DOUBLE code modeling of the NPA thermal hydrogen ion spectrum (solid squares), including passive and active neutral particle sources, at $t \sim 200 \mathrm{msec}$.

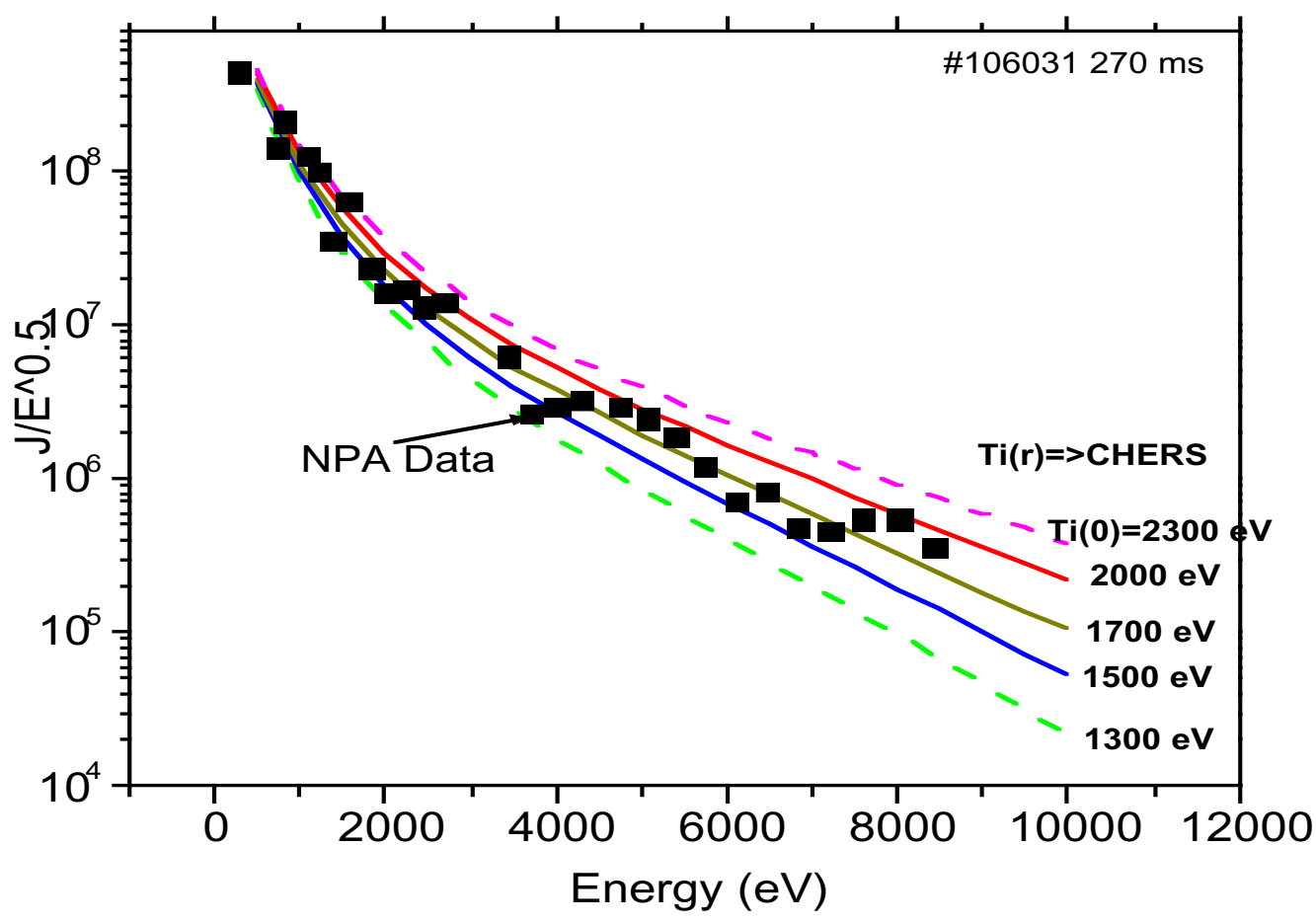

Figure 6. DOUBLE code modeling of the NPA thermal hydrogen ion spectrum (solid squares)at $t \sim 270 \mathrm{msec}$ with variation of $\mathrm{Ti}(0)$ demonstrating the fit sensitivity. 


\subsection{Effect of MHD Activity on Thermal Ion Distributions}

The appearance of magnetohydrodynamic (MHD) mode activity can have a pronounced effect on both the 'thermal' ( $E \sim 0.5-10 \mathrm{keV}$ ) and 'energetic' ( $\sim 10-100 \mathrm{keV}$ ) ion populations in NSTX. An example is presented in Figure 7 marked by the shaded vertical bar where panel (a) shows injection of a
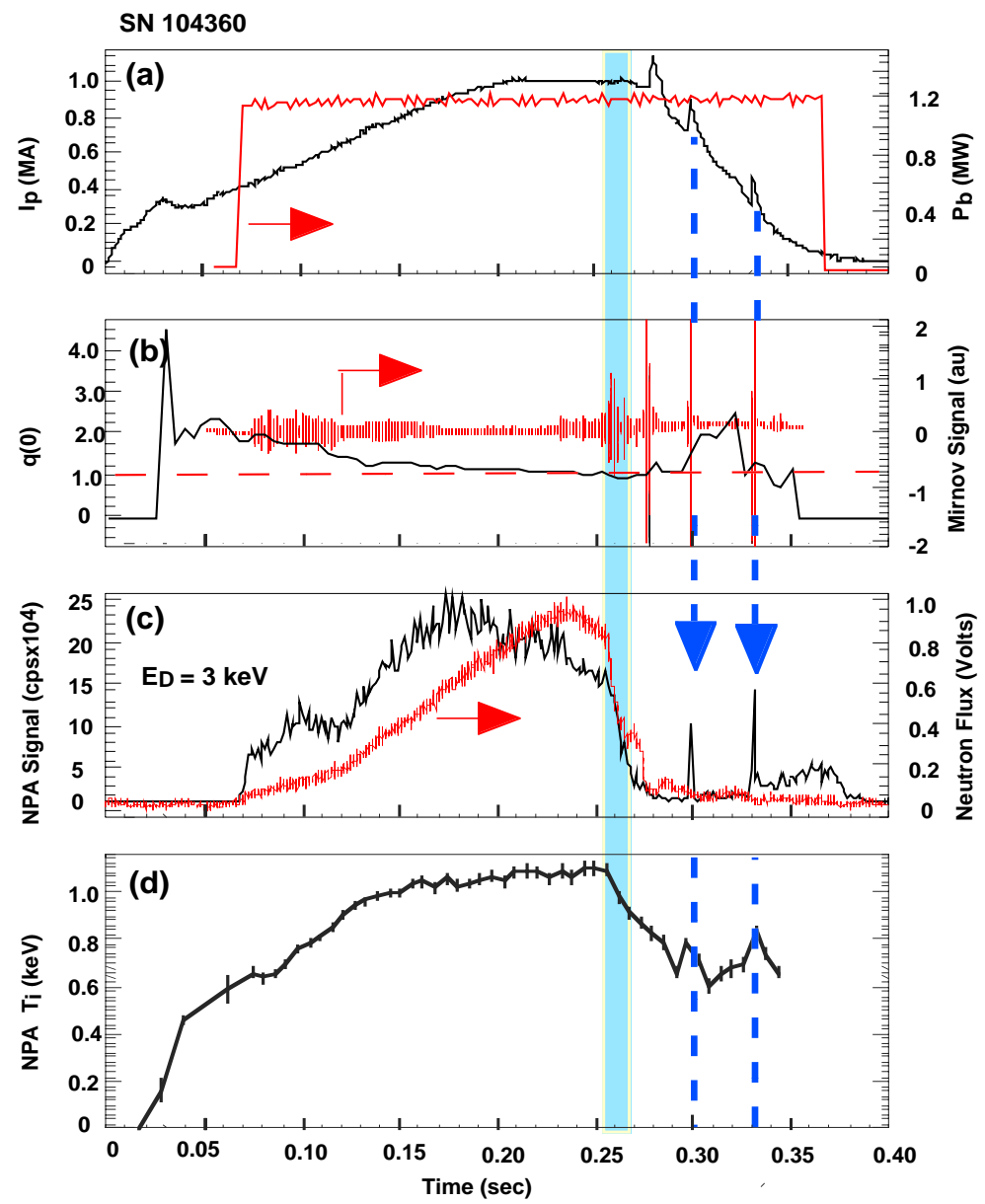

Figure 7. Illustration of the effects of MHD activity and internal reconnection events on the thermal ion distribution measured by the NPA diagnostic in NSTX peak NB power of $1.2 \mathrm{MW}$ during the 1 MA flat top of a deuterium discharge. Panel (b) shows the onset of large scale MHD activity at $\mathrm{t} \sim 0.26 \mathrm{sec}$ as indicated by the Mirnov coil measurements. Note that $\mathrm{q}(0) \leq$ 1 during this MHD activity. This activity is identified as an $n=2$ mode with frequency $\sim 20 \mathrm{kHz}$. As reported elsewhere [5], growth of the $n=2$ mode leads to rollover and relatively slow decay of the energetic ion population and consequently the neutron yield as shown in panel (c). Panel (c) shows thermal ions are also lost during MHD activity which results in a collapse in the ion temperature as seen in panel (d).

The effects of Internal Reconnection Events (IREs) and sawteeth on the thermal and energetic ion distributions in NSTX differ from that observed

for MHD mode activity. IREs are signatured by sharp upticks on the plasma current waveform (marked by dashed vertical lines). IREs are also evidenced as a sharp signal burst on the Mirnov waveform whereas other MHD activity exhibits more continuous signal fluctuations. In most cases, strong IREs are preceded by sawteeth or other MHD activity. At an IRE event, prompt loss of the energetic ions occurs on a fast time scale of $\leq 2 \mathrm{msec}$ [5] while the thermal ions remain confined but are redistributed outboard 
from the plasma core to a region of higher neutral density which leads to a burst in the neutral particle flux measured by the NPA as seen during the current rampdown at $t \sim 0.30 \mathrm{sec}$ and $t \sim 0.33 \mathrm{sec}$ in panel (c). Also a small increase in the apparent ion temperature can be seen in panel (d) at the time of the IREs. These observations are indicative of a redistribution of core ions to the plasma periphery where the neutral density is higher, thus producing the spike in the NPA flux and measured $T_{i}$. For reasons yet unknown, IREs occasionally have no effect on the NPA signal as can be seen for the IRE at the end on the current flattop in Figure 7.

The best way to determine if the rollover in the NPA ion temperature is due to MHD activity as marked by the shaded vertical bar in Figure 7 or due to the increasing plasma density as in Figure 2 is

to inspect the neutron waveform. MHD activity causes the neutron yield to rollover, but increasing plasma density does not.

\section{Acknowledgements}

This work was supported at PPPL by DOE Contract DE-AC02-76CHO3073 and Russian Foundation for Basic Research (RFBR) Grant No. 00-02-16970.

\section{References}

1. S. S. Medley, et al., Rev. Sci. Instrum. 69, 2651 (1998).

2. R. E. Bell, et al., PPPL Report "Kinetic Profiles in NSTX Plasmas," PPPL-3591 (1998).

3. Yu. N. Dnestrovskij, et al., Nucl. Fus. 19, 293 (1979).

4. A. I. Kisylakov, M. P. Petrov and E. V. Suvorkin, Plasma Phys. Control. Fusion 43, 1775 (2001).

5. S. S. Medley, et al., PPPL Report "Neutral Particle Analyzer Measurements of lon Behavior in NSTX," PPPL-3668 (2002) 


\section{External Distribution}

Plasma Research Laboratory, Australian National University, Australia

Professor I.R. J ones, Flinders University, Australia

Professor J oão Canalle, Instituto de Fisica DEQ/IF - UERJ , Brazil

Mr. Gerson O. Ludwig, Instituto Nacional de Pesquisas, Brazil

Dr. P.H. Sakanaka, Instituto Fisica, Brazil

The Librarian, Culham Laboratory, England

Library, R61, Rutherford Appleton Laboratory, England

Mrs. S.A. Hutchinson, JET Library, England

Professor M.N. Bussac, Ecole Polytechnique, France

Librarian, Max-Planck-Institut für Plasmaphysik, Germany

J olan Moldvai, Reports Library, MTA KFKI-ATKI, Hungary

Dr. P. Kaw, Institute for Plasma Research, India

Ms. P.J . Pathak, Librarian, Insitute for Plasma Research, India

Ms. Clelia De Palo, Associazione EURATOM-ENEA, I taly

Dr. G. Grosso, Instituto di Fisica del Plasma, Italy

Librarian, Naka Fusion Research Establishment, J AERI, J apan

Library, Plasma Physics Laboratory, Kyoto University, J apan

Research Information Center, National Institute for Fusion Science, J apan

Dr. O. Mitarai, Kyushu Tokai University, J apan

Library, Academia Sinica, Institute of Plasma Physics, People's Republic of China

Shih-Tung Tsai, Institute of Physics, Chinese Academy of Sciences, People's Republic of China

Dr. S. Mirnov, TRINITI, Troitsk, Russian Federation, Russia

Dr. V.S. Strelkov, Kurchatov Institute, Russian Federation, Russia

Professor Peter Lukac, Katedra Fyziky Plazmy MFF UK, Mlynska dolina F-2, Komenskeho Univerzita, SK-842 15 Bratislava, Slovakia

Dr. G.S. Lee, Korea Basic Science Institute, South Korea

Mr. Dennis Bruggink, Fusion Library, University of Wisconsin, USA

Institute for Plasma Research, University of Maryland, USA

Librarian, Fusion Energy Division, Oak Ridge National Laboratory, USA

Librarian, Institute of Fusion Studies, University of Texas, USA

Librarian, Magnetic Fusion Program, Lawrence Livermore National Laboratory, USA

Library, General Atomics, USA

Plasma Physics Group, Fusion Energy Research Program, University of California at San Diego, USA

Plasma Physics Library, Columbia University, USA

Alkesh Punjabi, Center for Fusion Research and Training, Hampton University, USA

Dr. W.M. Stacey, Fusion Research Center, Georgia Institute of Technology, USA

Dr. J ohn Willis, U.S. Department of Energy, Office of Fusion Energy Sciences, USA

Mr. Paul H. Wright, Indianapolis, Indiana, USA 
The Princeton Plasma Physics Laboratory is operated by Princeton University under contract with the U.S. Department of Energy.

\author{
Information Services \\ Princeton Plasma Physics Laboratory \\ P.O. Box 451 \\ Princeton, NJ 08543
}

Phone: 609-243-2750

Fax: 609-243-2751

e-mail: pppl_info@pppl.gov

Internet Address: http://www.pppl.gov 